\title{
RECENT RESEARCH OF SHEAR CONNECTION IN PREFABRICATED STEEL-CONCRETE COMPOSITE BEAMS
}

\author{
Dr Marko Pavlović* \\ Faculty of Civil Engineering, University of Belgrade, Belgrade, Serbia \\ Dr Milan Spremić \\ Faculty of Civil Engineering, University of Belgrade, Belgrade, Serbia \\ Dr Zlatko Marković \\ Faculty of Civil Engineering, University of Belgrade, Belgrade, Serbia \\ Dr Dragan Buđevac \\ Faculty of Civil Engineering, University of Belgrade, Belgrade, Serbia \\ Dr Milan Veljković \\ Luleå University of Technology, Sweden
}

Prefabrication of steel-concrete composite decks can improve their competitiveness and sustainability. This paper presents recent studies of longitudinal shear connection at the University of Belgrade, Faculty of Civil Engineering. Grouped welded headed studs and bolted shear connectors, suitable for prefabricated composite construction, has been examined in push-out tests. Totally 30 tests were conducted, and advanced FEA were made using Abaqus/Explicit dynamic solver. Based on the experimental and numerical studies behaviour those two shear connectors are compared.

Key words: Prefabricated composite beams, Grouped headed studs, Bolted shear connectors

\section{INTRODUCTION}

Steel-concrete composite beams have been used in buildings and bridges for decades. Insitu casted concrete often requires temporary supports and formwork. Prefabrication of concrete slabs is a good way to reduce the construction time and optimize the construction process. Composite action between a steel profile and a concrete slab is most commonly established by grouting grouped headed studs welded to the top flange of the steel section in envisaged openings

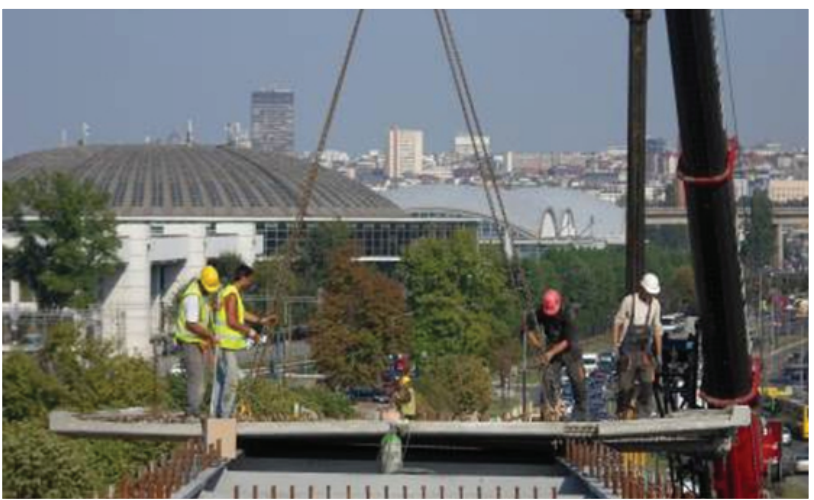

(pockets) in prefabricated concrete slabs (see Figure 1). A possible alternative solution is to use high-strength bolts to establish longitudinal shear connection. Bolts can be casted in prefabricated concrete slabs (see Figure 2) and on site assembled to the predrilled top flange of the steel section part of composite member. This solution offers great prefabrication benefits, since no time is needed for grout hardening. Usage of bolted shear connectors also improves the sustainability of construction as the structure will have to be removed at the end of its lifetime.

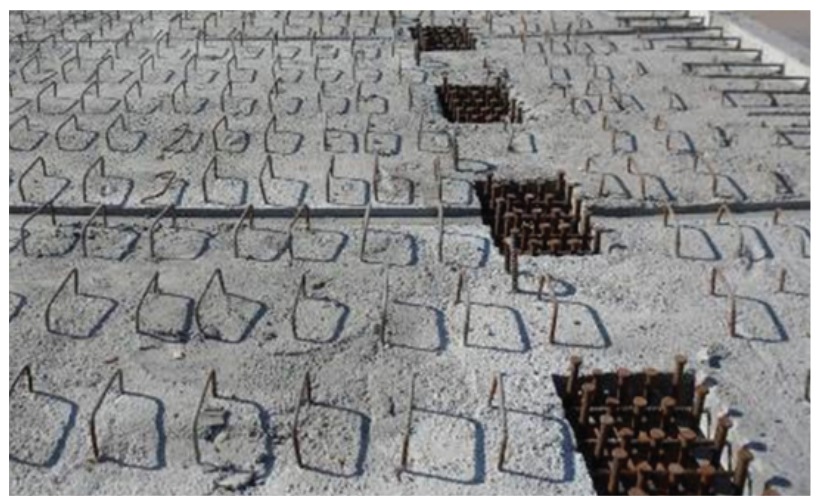

Figure 1: Prefabricated concrete slabs with openings for grouped shear connectors

${ }^{*}$ Faculty of Civil Engineering, Bulevar kralja Aleksandra 73, 11000 Belgrade, Serbia 

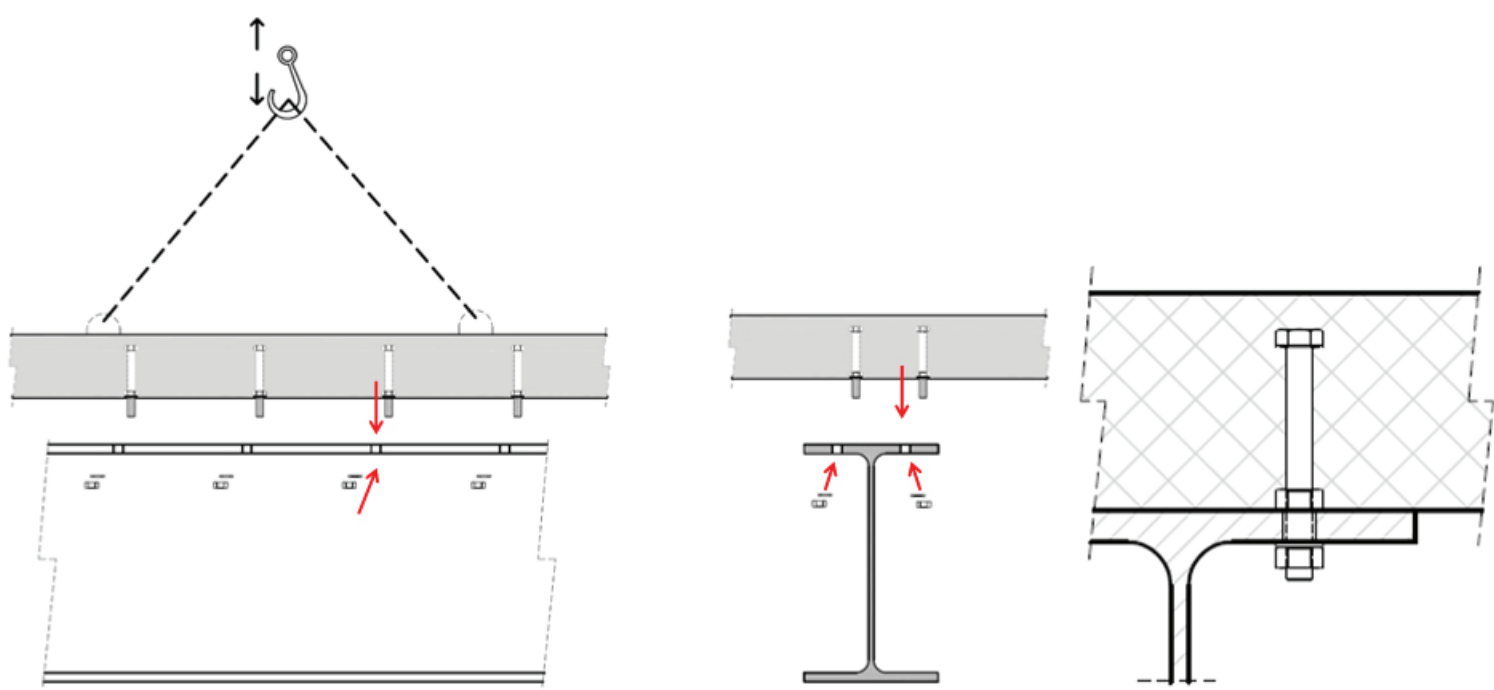

Figure 2: Possible application of bolted shear connectors embedded in prefabricated concrete slabs

Apart from evident benefits arising from application of the mentioned solutions, there are still no specific design rules in design codes, which is an obstacle for their wide application. Possible reason could be the lack of detailed research of specific behaviour of such shear connections. For example, EN1994-2 [01] (Eurocode 4 for bridges) allows usage of headed studs in grouped arrangement, but only some general recommendations are given. According to [01] following facts need to be considered: the non-uniform flow of longitudinal shear, the greater possibility of slip and vertical separation between the slab and the steel member, buckling of the steel flange and the local resistance of the slab to the concentrated force from the connectors. Additionally, it is given that in the case of grouped arrangement the longitudinal spacing of groups may be greater than the maximum allowed spacing for individual shear connectors, but the limits are not given.

The principle of usage of grouped headed studs can be explained as shown in Figure 3 by replacing the block shear connector with group of headed studs. Research on grouped arrangement of welded headed studs, in last two decades, is pointed towards the reduction of longitudinal spacing between the studs within the group. This would allow smaller openings that are needed to accommodate the groups of studs in prefabricated concrete slabs and therefore more compact concrete slab with less discontinuities. Previous studies, conducted by Okada et al. [02] and Shim et al. [03], investigated the shear capacity of nine large headed studs (22 $\mathrm{mm}$ and $25 \mathrm{~mm}$ ) arranged in groups with reduced longitudinal spacing between studs. These studies were intended for studying grouped studs application in precast composite bridge structure. These authors suggested the reduction coefficient for individual shear resistance of studs when arranged in groups. Suggested coefficients are in function of longitudinal spacing between the studs.

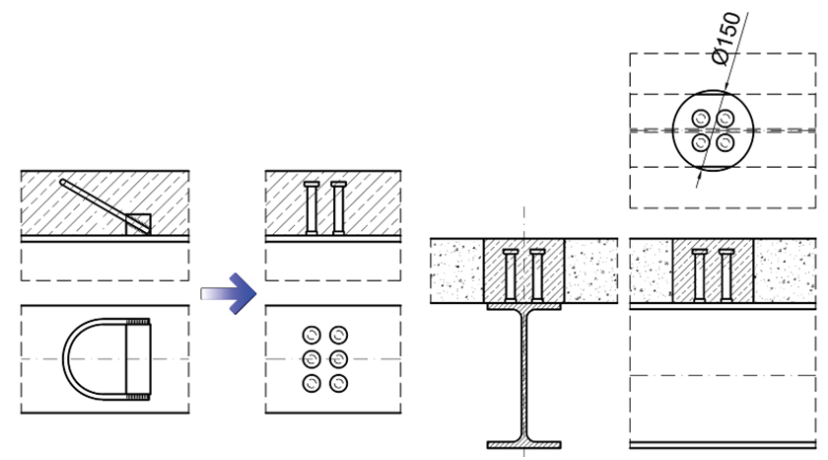

Figure 3: The principle of replacing the block shear connector with grouped headed studs

Possible uses of bolted shear connectors are shown in Figure 4. The composite action can be established with or without nuts embedded in the slab, either with or without preloading of the bolts. They have been investigated by several previous studies: Marshall et al. [04], Dedic and Klaiber [05], Hawkins [06], Sedlacek et al. [07], ,Kwon [08], Lee and Bradford [09]. Except for the friction grip bolts, shown in Figure $4 a$, none of the mentioned studies gave the detailed explanation of behaviour of such shear connectors, and the design rules in worldwide design codes are still not present. 
The research program considering solutions for longitudinal shear connection in prefabricated composite construction is being realised on University of Belgrade - Faculty of Civil Engineering in recent years, through $\mathrm{PhD}$ theses of Spremić [10] and Pavlović [11]. Experimental and numerical studies was conducted with the aim to analyse possibilities to use grouped headed studs in prefabricated composite beams in buildings. The group of four studs with $16,0 \mathrm{~mm}$ diameter has been investigated. Basic shear connector's properties have been investigated throughout the study such as: shear resistance, stiffness and ductility, as well as the possibility to reduce the spacing between adjacent headed studs in the group. Bolted shear connectors with single embedded nut, shown in Figure 4c, were considered because they have much higher shear stiffness when compared to other types. In addition, they are more suitable for casting in prefabricated concrete slabs since they can be mounted by the nuts on both sides to a template in the formwork.

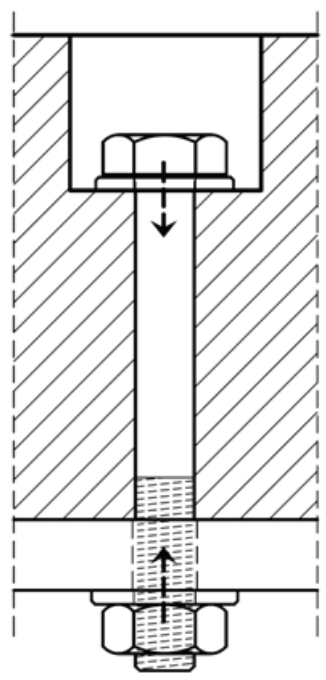

a) friction grip bolt

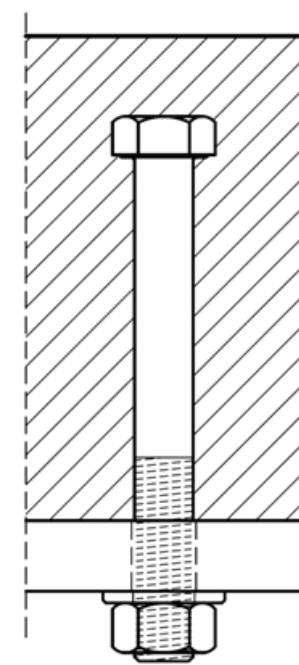

b) without embedded nut

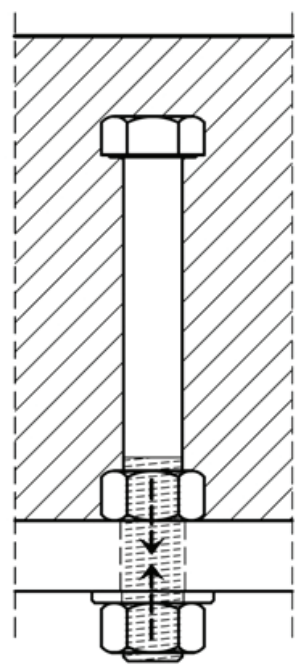

c) single

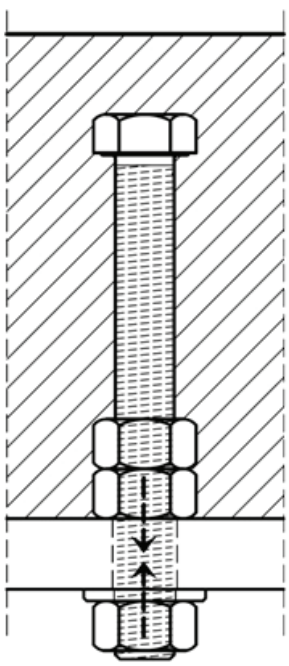

d) double embedded nut embedded nuts

Figure 4: Different types of bolted shear connectors

\section{EXPERIMENTAL WORKS}

Experimental works included 30 standard pushout tests: 24 test with grouped studs and 8 test with bolted shear connectors. The materials, initial assumptions and test set up were in accordance with EN1994-1-1 [12]. The layout of specimens is shown in Figure 5.

The study considered five different groups of four headed studs, with the distance between headed studs less than the minimum distances required in EC4 [1] and [12]. The layout of group arrangement along with its orientation to the applied load and distance between the studs were the variables that were considered (see Figure $6 a$ ). The aim was to determine how does the reduction of the minimum required spacing between the headed studs affects the behaviour of the shear connection: shear resistance, ductility and total longitudinal shear deformation. Analysed groups were formed with longitudinal spac- ing between the studs $\mathrm{s}=45 \mathrm{~mm}(2.8 \mathrm{~d})$ to $\mathrm{s}$ $=50 \mathrm{~mm}$ (3.1d). The push-out specimens GR1, G1 were constructed with deferent types of precast concrete slabs. The concrete slabs without reinforcement bars in front of the studs groups were used for the push-out specimens $\mathrm{G} 1$. Bolts grade 8.8, with diameters M16 and M24, were examined experimentally (see Figure 6b), while other diameters were considered through a parametric FEA study.

Specimens were assembled in two phases, one side than another, by concreting openings in horizontal position (see Figure 7a). Upon 28 days after specimen preparation, they were equipped with sensors mounts, and put into testing frame with hydraulic jack. Each specimen was equipped with 8 LVDTs (Linear Variable Displacement Transducer), as shown in Figure $7 \mathrm{~b}$ in order to measure the longitudinal slip and separation between steel flange and the concrete slabs. 


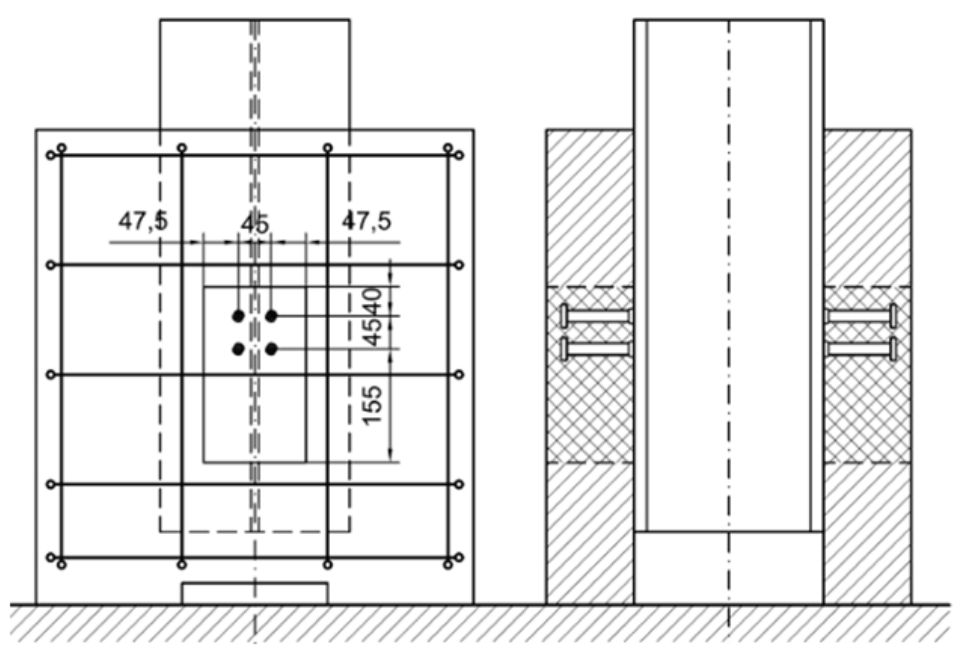

a) grouped headed studs

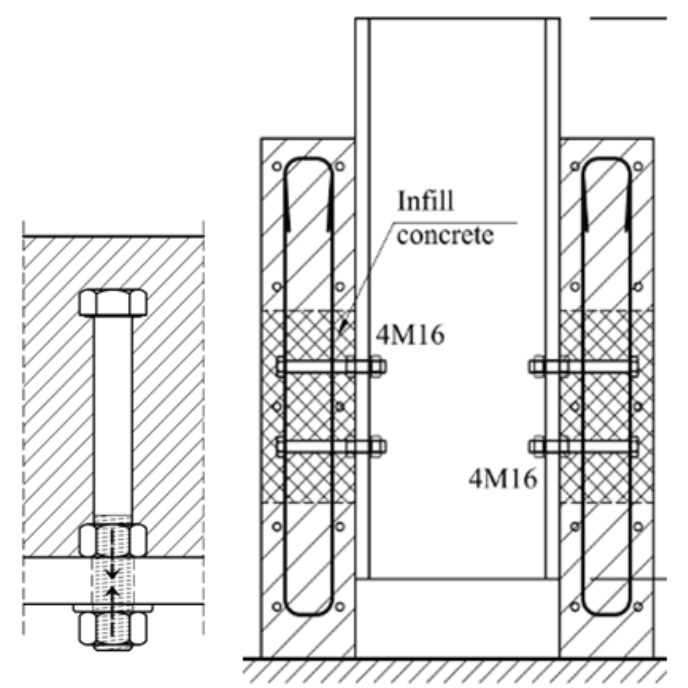

b) bolted shear connectors

Figure 5: Push-out tests layout

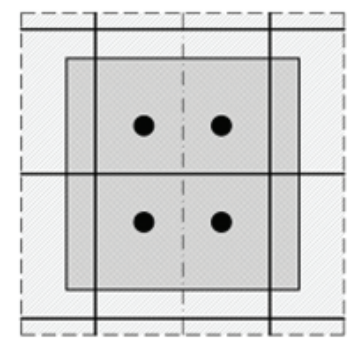

ST

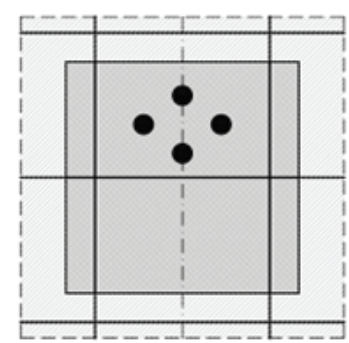

LDA2

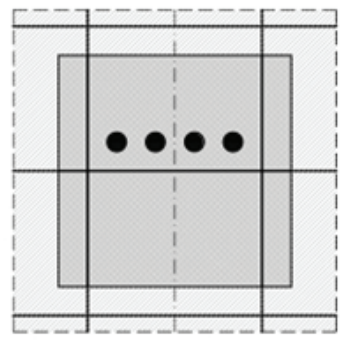

TDA

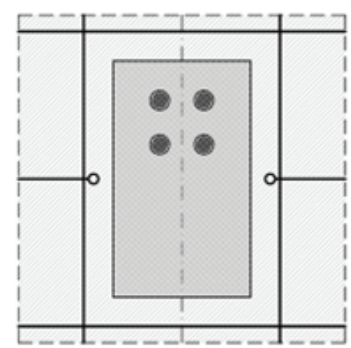

G1

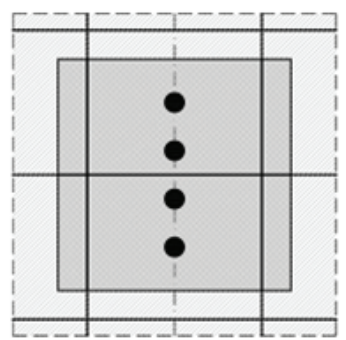

LDA1

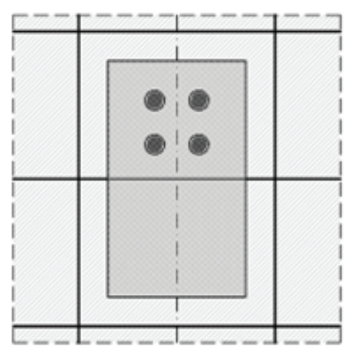

GR1

a) grouped headed studs

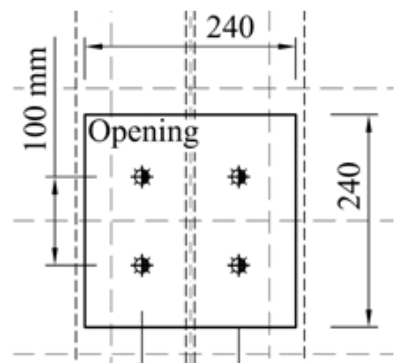

$\mathrm{BSC}-4 \mathrm{xM} 16$

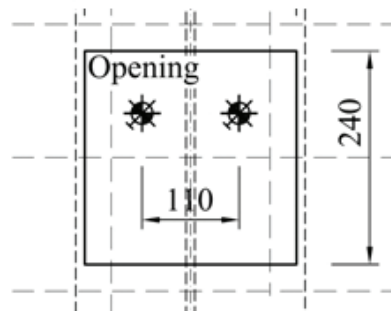

BSC - 2xM24

b) bolted shear connectors

Figure 6: Different arrangements of grouped headed studs and diameters of bolted shear connectors analysed in the study

The force was measured by a load cell at the top, with capacity of $1000 \mathrm{kN}$.

Results of push-out tests are presented in Figure 8 as averaged force-slip curves (within the 4 specimens) for different types of shear connection examined. All results of push-out tests with headed studs group have the ultimate shear resistance greater then characteristic shear resistance according to EC 4 [01] and [12]. The values of ultimate shear resistance of the group arrangements $\mathrm{G} 1$ and GR1, LDA2, with two headed studs in the direction of the load at a smaller distance than recommended $5 \mathrm{~d}$ are the same or higher than the ultimate bearing resis- tance of standard ST type specimens. Average values of ultimate failure load for the G1 type specimens and GR1 type specimens demonstrate that transversal reinforcement in the slab does not have considerable influence on the shear resistance. Bolted shear connectors M16 showed similar shear resistance as the comparable headed studs, while bolts M24 reached much higher shear resistance, with ductile behaviour. Two types of failure modes were recognized for bolted shear connectors: shear failure of the connector and pryout failure of the concrete in front of the shear connector. 


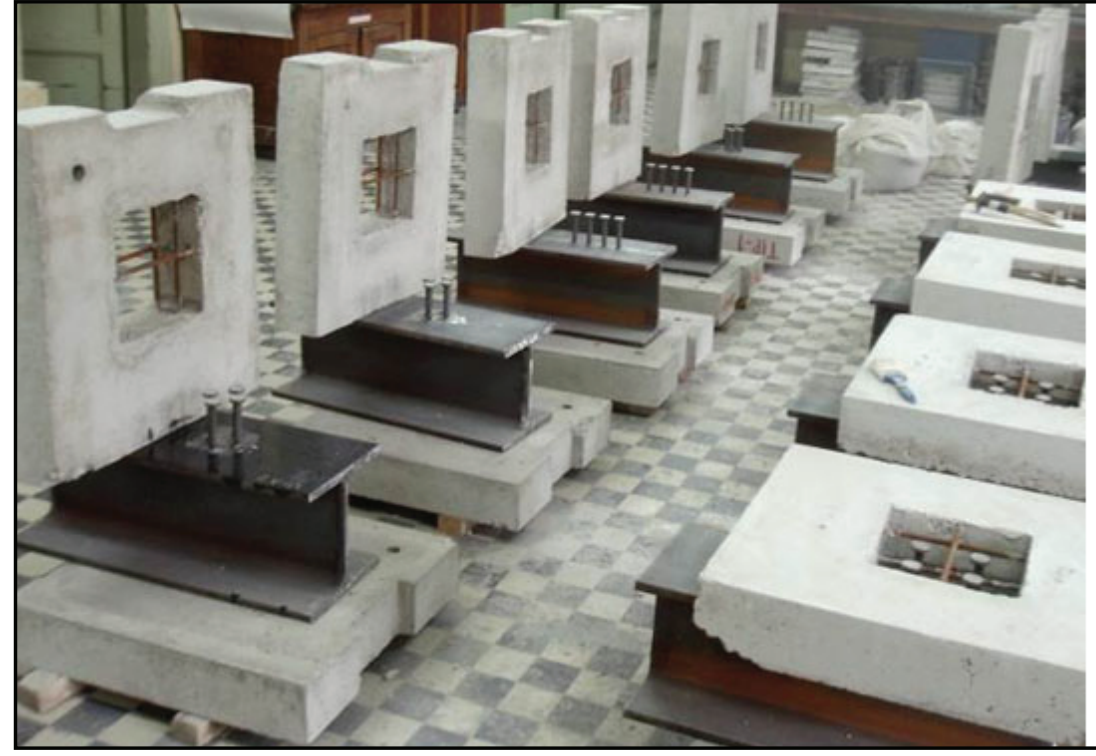

a) half assembled specimens

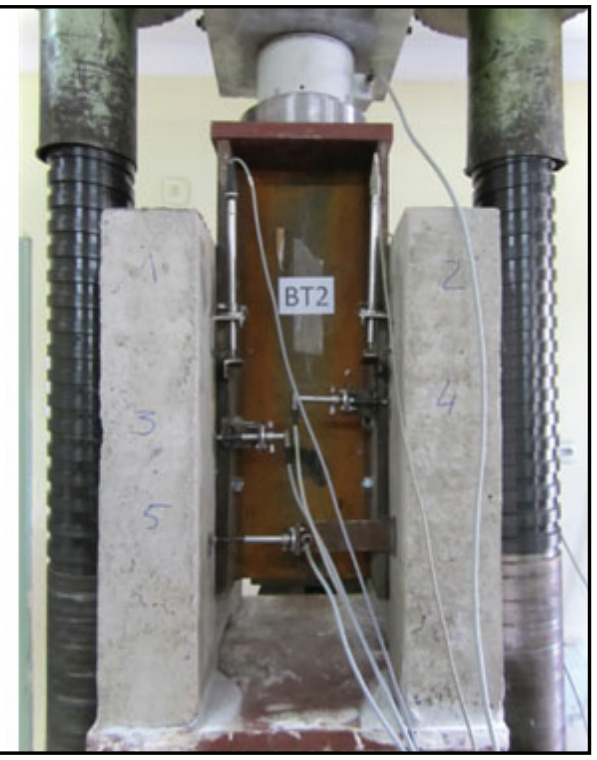

b) measurements layout

Figure 7: Assembling of the specimens and testing in the hyraulic jack

\section{NUMERICAL FEA STUDIES}

Extensive advanced finite element analyses (FEA) were conducted alongside the experimental works as illustrated in Figure 9. Firstly, the verification FEA was made in order to calibrate the models by matching the results to push-out test. ABAQUS/Explicit solver with damage material models were used to get more insight into behaviour of the specimens and failure modes. Afterwards, those models were used for parametric studies with aim to develop design recommendations. Some of the results have already been published in [13] and [14].

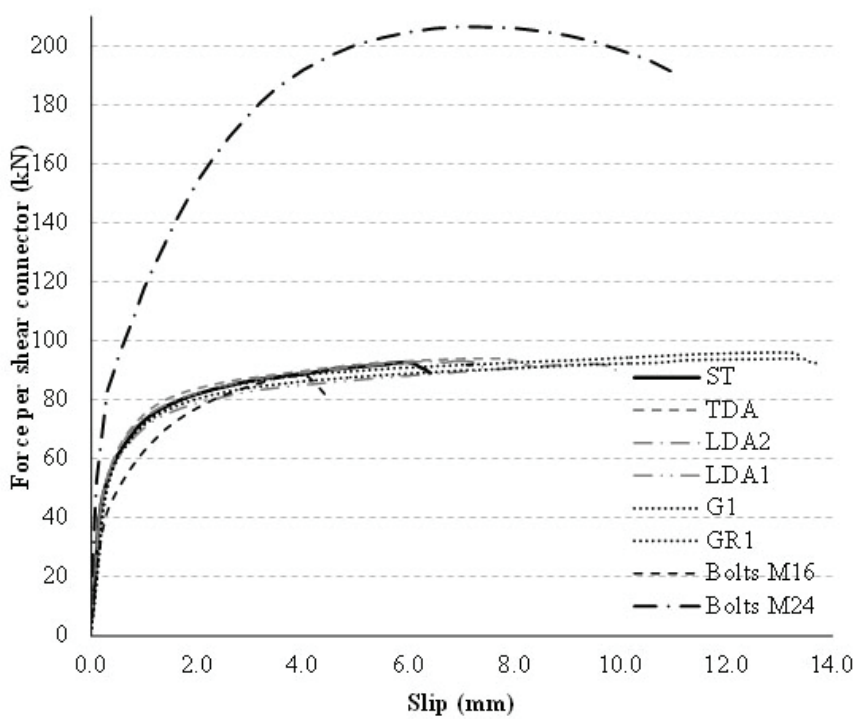

Figure 8: Averaged force-slip curves for different arangements of grouped headed studs and diameters of boltes shear connectors

\section{CONCLUSION}

Based on the results of presented study it is concluded that prefabrication of steel-concrete composite beams by use either of grouped headed studs or bolted shear connectors is feasible. This study went beyond the state-of-the-art giving the practical design recommendations for those types of shear connection. A concept of equivalent diameter of group of headed studs is introduced in [13] and a reduction factor for shear resistance of headed studs in groups is derived as its function. Complete calculation models for shear resistance and ductility of bolted shear connectors were developed in [14] based on two possible failure modes (bolt and concrete). Moreover, pryout failure of the concrete has been explained analytically for the first time. Design recommendations, both in cases of grouped headed studs and bolted shear connectors, are proposed in a form which is suitable for adoption in EC4.

\section{ACKNOWLEDGEMENTS}

The study presented in this paper is supported by the Serbian Ministry of Education, Science and Technological Development through the TR36048 project. Support provided by "MB steel" Ltd. and "GEMAX" Concrete production Ltd. from Belgrade was beneficial for specimen production. 

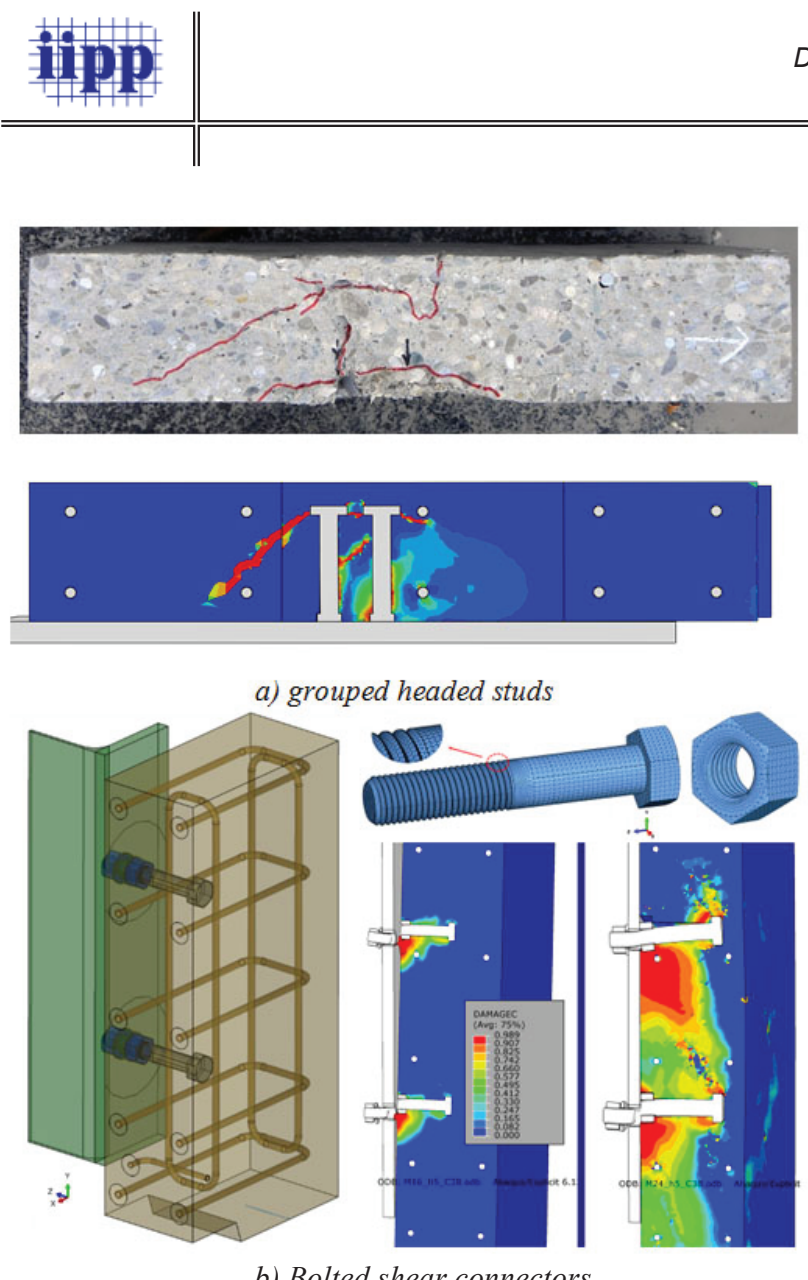

b) Bolted shear connectors

Figure 9: Finite element analyses of tested specimens and parametric studies

\section{REFERENCES}

1) Dedic DJ, Klaiber WF. High-Strength Bolts as Shear Connectors in Rehabilitation Work. Concrete international 1984;6(7):41-46.

2) EN1994-1-1: Eurocode 4 - Design of composite steel and concrete structures. Part 1-1: General rules and rules for buildings. Brussels, Belgium: European Committee for Standardization (CEN); 2004.

3) EN1994-2: Eurocode 4 - Design of Composite Steel and Concrete Structures. General Rules and Rules for Bridges. Brussels, Belgium: European Committee for Standardization (CEN); 2005.

4) Hawkins N. Strength in shear and tension of castin-place anchor bolts. Anchorage to Concrete 1987;SP-103:233-255.

5) Kwon G. Strengthening existing steel bridge girders by the use of post-installed shear connectors. $\mathrm{PhD}$ thesis. The University of Texas at Austin, 2008:p.239.
6) Lee M. Bradford MA. Sustainable composite beam behaviour with deconstructable bolted shear connectors. Proceedings of the 2013 Composite Construction in Steel and Concrete VII.

7) Marshall WT, Nelson HM, Banarjee HK. An experimental study of the use of high strength friction-grip bolts as shear connectors in composite beams. The Structural Engineer 1971;49(4):171178.

8) Okada J, Teruhiko Y, Lebet JP., A study of the grouped arrangements of stud connectors on shear strength behaviour, Structural Eng./Earthquake Eng.,JSCE 2006;23(1):75-89.

9) Pavlović M, Marković Z, Veljković M, Budjevac D, Bolted shear connectors vs. headed studs behaviour in push-out tests, Journal of Constructional Steel Research 2013;88:134-149.

10) Pavlović M., Resistance of bolted shear connectors in prefabricated steel-concrete composite decks, PhD thesis, University of Belgrade, Faculty of Civil Engineering; 2013.

11) Sedlacek G. Hoffmeister B. Trumpf H. Kühn B. et al. Composite bridge design for small and medium spans. Final report. European Commission - technical steel research Contract No 7210PR/0113. Luxembourg, 2003.

12) Shim CS, Lee, PG, Kim DW, Chung $C H$., Effects of Group Arrangement on the Ultimate Strength of Stud Shear Connection. Proceedings of the 2008 Composite Construction in Steel and Concrete Conference VI, ASCE Conf. Proc.

13) Spremić M, Marković Z, Veljković M, Budjevac D., Push-out experiments of headed shear studs in group arrangements, Advanced Steel Construction; 2013,9(2):170-191.

14) Spremić M., The analysis of headed studs group behavior in composite steel-concrete beam, PhD thesis, University of Belgrade, Faculty of Civil Engineering; 2013.

Paper sent to revision: 07.02.2014.

Paper ready for publication: 15.03.2014. 